\title{
Effect of Deep Excavations on Adjacent Structures and Importance of Deep Excavation Support
}

\author{
Nagham Ghamraoui ${ }^{1}$, Diala Tabbal ${ }^{1}$ \\ ${ }^{1}$ Beirut Arab University \\ Tripoli, Lebanon \\ Nyg199@student.bau.edu.lb; d.tabbal@bau.edu.lb
}

\begin{abstract}
When deeply excavating close to existing structures, displacements in the soil under the base of the existing structure will occur. Therefore, considerable settlement will take place. Accordingly, it's so necessary to understand and evaluate the soil's behavior for excavations adjacent to existing structures.

The goal of this paper is to evaluate the response of structures when deeply excavating near them. Finite Element models are generated using both 2D and 3D PLAXIS software. The excavation is reinforced by diaphragm walls, struts, and wales. The influence of the supporting system on the adjacent existing structure is examined and analyzed in details. A parametric study is carried out to examinate the factors that may have influence on the excavation. For the final step, some conclusions and recommendations of future researches will be sorted out.
\end{abstract}

Keywords: Existing structures, deeply excavating, Finite Element model, displacements.

\section{Introduction}

The world's population is highly increasing, and this rapid growth has led to a high urban evolution as well. Thus, it became so important to find modern solutions regarding the ever-increasing demand for usable spaces. The number-one found solution to profit from every area in a crowded city was the use of underground constructions. Thus, it became so important to construct deep excavations, that has supplied cities with more areas that can be taken advantage of. Underground constructions can be used for parking, tunnels, water transport, material storage, subways, and much more.

When excavating the soil's behavior variate, particularly close by the excavation area. It begins to lose its consistency, therefore changes in stress as well as strains begin. Those changes will definitely affect the stability of the adjacent existing structures and their foundations. Consequently, acknowledging the soil's behavior for every excavation case and finding the best ways to protect those excavations in order to help them maintaining their stability without causing damages to nearby structures became a very important requirement.

Research and studies concerning this topic have been established by a number of researchers. (Horodecki \& Dembicki, 2012) [1] have studied the impact of deep excavations on nearby urban areas. (Sevencan et al., 2013) [2] have conducted a numerical analysis of soil deformations around deep excavations which was executed using top-down construction method with diaphragm walls. (Ebraheem Ramadan et al., 2013) [3] have conducted an analysis about piles supporting excavation adjacent to existing buildings that aims to provide suggestions concerning the design of contiguous pile walls for cohesive soils. (Dhatrak et al., 2016) [4] conducted a study that aims to investigate the effect of an excavation on the behavior of a pile foundation of an existing nearby building. (Zumrawi \& El-Amin, 2016) [5] studied also the importance of deep excavation supporting systems and their influence on nearby structures.

\section{Numerical Modelling}

\subsection{Model Geometry}

The excavation is $12.0 \mathrm{~m}$ deep, and $25.5 \times 29.0 \mathrm{~m}$ wide. It's surrounded by two buildings of six floors each. The excavation will be supported using a braced system that consists of $17.0 \mathrm{~m}$ deep diaphragm walls, struts, and wales. The excavation is divided into three stages, the first excavation level is at $-1.5 \mathrm{~m}$, the second one is at $-7.0 \mathrm{~m}$, and the final excavation level is at $-12.0 \mathrm{~m}$. For the soil layers, clay 1 is from 0 to $-5.0 \mathrm{~m}$, the second layer is a sandy soil layered from $5.0 \mathrm{~m}$ to $-8.0 \mathrm{~m}$, and the final one is clay 2 layered from $-8.0 \mathrm{~m}$ and below. The struts are installed $0.5 \mathrm{~m}$ above each excavation 
level, which means that they will be installed at $-1 \mathrm{~m}$ and $-6.5 \mathrm{~m}$. A plan view of the excavation and its surrounding is represented in Figure 2-1.

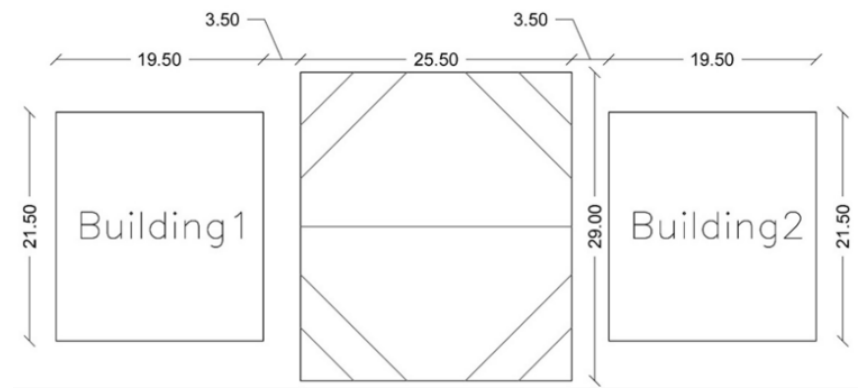

Figure 2-1: Geometry of the excavation and its surrounding

\subsection{Loading Conditions}

The excavation area is surrounded by two buildings, each of six floors. Taking $1.5 \mathrm{~T} / \mathrm{m}^{2}$ for one floor for buildings, subsequently will give us $90 \mathrm{kN} / \mathrm{m}^{2}$ as for building loads.

\subsection{Material Properties}

Hardening soil model will be used for the models. For the material type, all soil layers are drained, thus the soil friction and the cohesion are defined. In contrary, the pore index as well as the permeability won't be defined. Three soil layers are defined, "Clay 1" from 0 to $-5.0 \mathrm{~m}$, with $\gamma_{\text {unsat }}$ and $\gamma_{\mathrm{nsat}}$ equal to 17 and $18 \mathrm{kN} / \mathrm{m}^{3}$ respectively and a cohesion equal to 15 . Layer 2 is a sandy soil of $\gamma_{\text {unsat }}$ equal ro $\gamma_{\mathrm{nsat}}$ equal to $18 \mathrm{kN} / \mathrm{m}^{3}$ and $\mathrm{c}=1 \mathrm{kN} / \mathrm{m}^{2}$, this layer varies from $-5.0 \mathrm{~m}$ to $-8.0 \mathrm{~m}$. Finally, layer 3 is "Clay 2" with $\gamma_{\text {unsat }}$ and $\gamma_{\text {nsat }}$ equal to 17 and $18 \mathrm{kN} / \mathrm{m}^{3}$ respectively and a cohesion equal to $30 \mathrm{kN} / \mathrm{m}^{2}$.

Two plates were defined for our model: diaphragm walls of $60 \mathrm{~cm}$ thick each, and buildings represented by $80 \mathrm{~cm}$ thick plates with $\gamma=24 \mathrm{kN} / \mathrm{m}^{3}$ and $\mathrm{E}=2.20 \mathrm{E}+07 \mathrm{kN} / \mathrm{m}^{2}$ for each. All the plates are defined as elastic and isotropic. The use of elastic material type facilitates the calculations, and in fact the walls behave elastically, which justify the use of this material type.

Wales are defined as HEA 500 steel beams.

Struts are defined as struts with axial stiffness, $\mathrm{EA}=3.77 \mathrm{E}+06 \mathrm{kN} / \mathrm{m}$.

\subsection{Mesh Generation And Calculation Stages}

The main concept of FEM models is to divide them into parts, which is translated by the mesh. It's known that using a fine mesh give more accurate results, but lead to a bigger analysis time. Subsequently, and in order to get the most accurate results during a reasonable period of time, global refinement will be generated.

For this model, we will be using a medium mesh with local refinement in the excavation area, near the plates, and finally under the loads as well.

The calculation stages are as follow: loads activation, activation of diaphragm walls and interfaces, proceeding with first level of excavation, installation of first level of struts, proceeding with the second level of excavation, installation of the second level of struts and finally ending with the final level of excavation. We can add the final stability stage, by choosing the Phi/c reduction as a calculation stage, in order to observe the factor of safety.

\subsection{Modeling Results And Discussions \\ 2.5.1 Heave}

Heave is equal to $3.8 \mathrm{~cm}$ and $3.3 \mathrm{~cm}$ for $3 \mathrm{D}$ and $2 \mathrm{D}$ models respectively.

The maximum heave value is slightly greater in 3D model than 2D model, so we can approximately say that heave is similar in 2D and 3D models. 


\subsubsection{Settlement of nearby building}

Comparing 2D and 3D models, the settlements of the building are $-1.25 \mathrm{~cm}$ and $-1.3 \mathrm{~cm}$ respectively.

The settlements are almost the same in 2D and 3D models, and are represented in the chart of Figure 2-2.

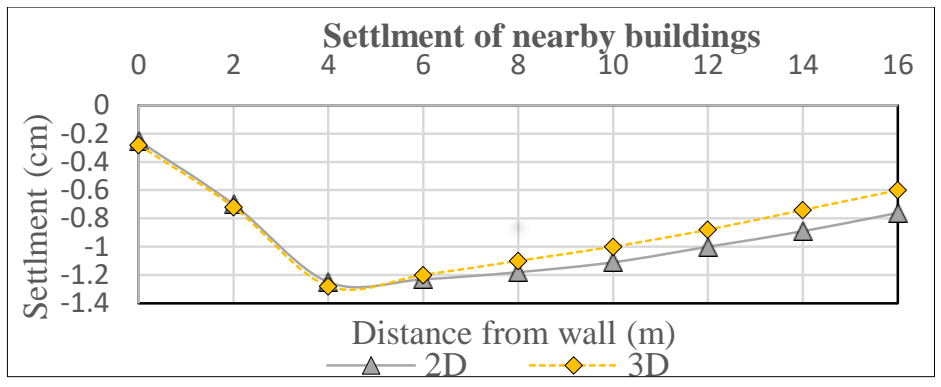

Figure 2-2: Settlement of nearby building for 2D and 3D models

\subsubsection{Bending moment of wall}

Concerning bending moments, a comparison is shown in the chart of Figure 2-3. The maximum absolute bending moment value for 2D and 3D models respectively are $368.4 \mathrm{kNm} / \mathrm{m}$ and $359.3 \mathrm{kNm} / \mathrm{m}$. Maximum absolute bending moment for $2 \mathrm{D}$ is $2.5 \%$ greater than maximum absolute bending moment for $3 \mathrm{D}$, which means they are approximately the same.

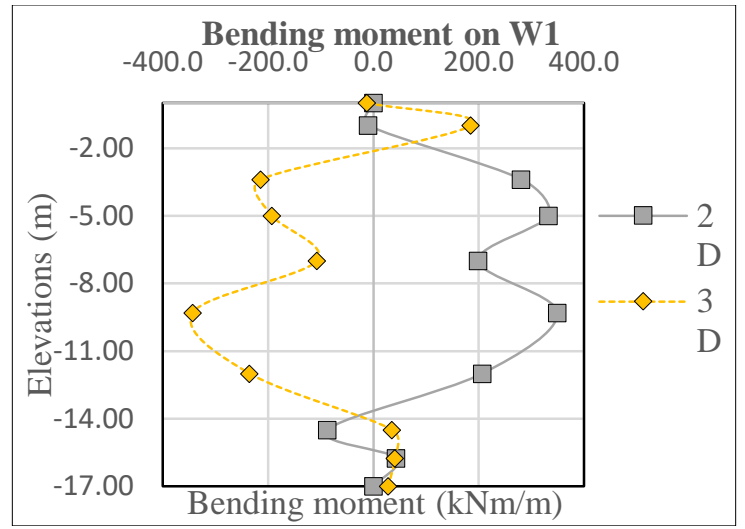

Figure 2-3: Bending moment on $\mathrm{W} 1$ for 2D and 3D models

\subsubsection{Forces in struts}

Figure 2-4 shows the struts' enumeration and Error! Reference source not found. represents the values of forces in struts for 2D and 3D models. 


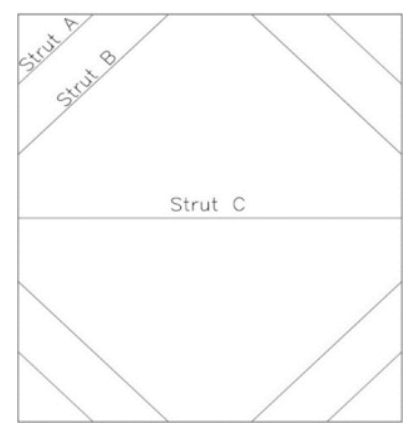

Figure 2-4: Plan view of the excavation showing struts' enumeration

Table 2-1: Forces in struts

\begin{tabular}{|l|c|c|}
\cline { 2 - 3 } \multicolumn{1}{c|}{} & 2D & 3D \\
\hline Strut level 1 A & - & 679.65 \\
\hline Strut level 1 B & - & 811.8 \\
\hline Strut level 1 C & 851.36 & 1125.75 \\
\hline Strut level 2 A & - & 2009.03 \\
\hline Strut level 2 B & - & 2080.1 \\
\hline Strut level 2 C & 2096.11 & 2098.81 \\
\hline
\end{tabular}

Table 2-1 confirms that the forces of struts have higher values in 3D models than 2D models, yet corner struts can't be simulated in 2D models.

\subsubsection{Summary}

Reinforcement in corners can't be shown in 2D model, yet in 3D everything can be simulated as it really is. Thus, 3D models can illustrate the reality in all its details, thus our following parametric studies will be performed and analyzed using PLAXIS 3D.

\section{Parametric Studies}

\subsection{Load Designed As Building Compared To Load Designed As Plate}

In the previous sections, the buildings were represented as plates with surface loads in order to simplify the work. In another hand, buildings are modeled as buildings usually when structural element is a question of study.

In the following, we will be comparing two cases where the building is modeled first as a plate and second as a building; So, we can conclude how accurate it is to model the building as a plate subjected to a surface load. Case "A": building modeled as plate with surface load, Case "B": building modelled as building.

\subsubsection{Heave}

Heave is respectively equal to $3.8 \mathrm{~cm}$ and $3.15 \mathrm{~cm}$ in case (A) and case (B). The difference is equal to $17 \%$.

\subsubsection{Settlement of nearby building}

Settlement of nearby building for both cases (A) and (B) are represented in the chart of Figure 3-1. 


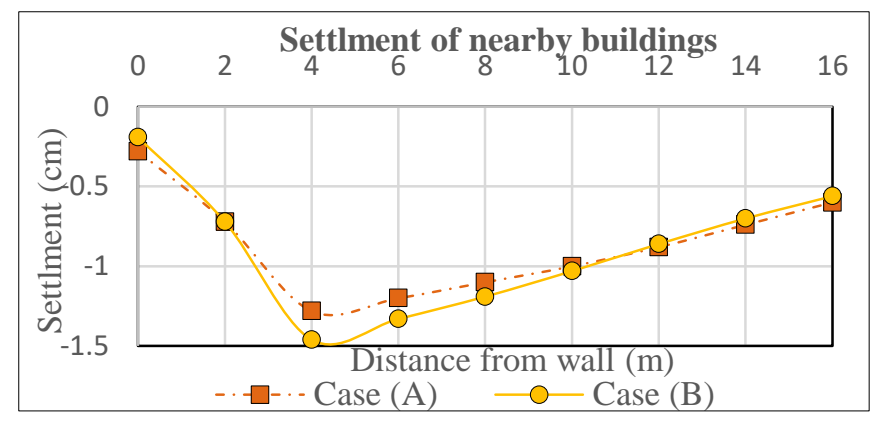

Figure 3-1: Comparison between settlement of nearby building in Case A and Case B

As we can see in the chart of Figure 3-1, the maximum settlement of the nearby building in case (A) is equal to $1.3 \mathrm{~cm}$ and case (B) is $1.5 \mathrm{~cm}$. The difference is equal to $4 \%$.

\subsubsection{Horizontal displacement of wall}

Horizontal displacements of wall for both cases (A) and (B) are represented in the chart of Figure 3-2.

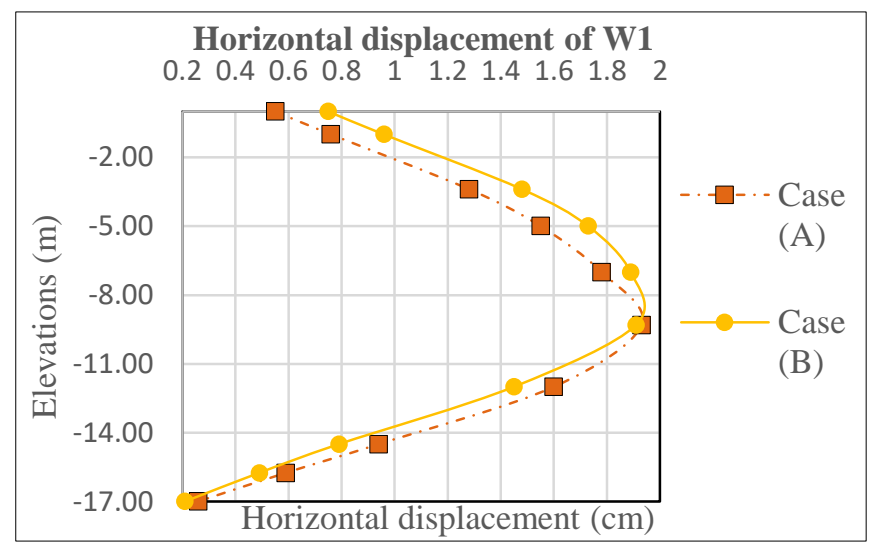

Figure 3-2: Comparison of horizontal displacement of wall in Case A and Case B

As we can see in Figure 3-2, the maximum displacement of wall $\mathrm{U}_{\mathrm{x}}$ in Case A is same for Case B and equal to $1.93 \mathrm{~cm}$.

\subsubsection{Bending Moment of Wall}

Bending moments of wall for both cases (A) and (B) are represented in the chart of Figure 3-3. 


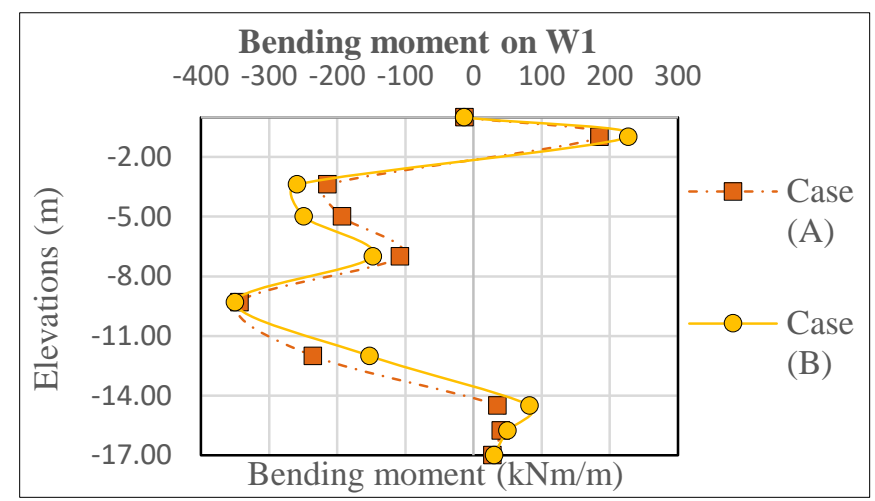

Figure 3-3: Comparison of bending moment of wall in Case (A) and Case (B)

As we can see from the chart of Figure 3-3, the maximum absolute bending moment value of wall in case (A) is equal to $359.3 \mathrm{kNm} / \mathrm{m}$ and case (B) is $354.4 \mathrm{kNm} / \mathrm{m}$. The difference is equal to $1.4 \%$.

\section{Conclusions}

In this study, an attempt to give a better understanding of the soil-structure interaction in a deep excavation neighboring an existing structure is shown.

In order to optimize the excavation model, a comparison between $2 \mathrm{D}$ and 3D numerical analyses are performed using Hardening soil models. Recommendations will be given about the better soil model to be adopted when modelling such problems. Then a series of parametric studies covering different configuration of excavations under different conditions are simulated and compared.

Main conclusions obtained from the research can be summarized as follow:

- Heave value is $17 \%$ greater in the case in which the building is modeled as a plate than in the case where the building is modeled as a whole building. Thus, the way the building is modelled has an impact on the heave value.

- The settlement of nearby building is $4 \%$ greater when the building is modeled as a whole building than when it's modeled as a plate. Thus, the way the building is modelled has a very small impact on the nearby building's settlement.

- The maximum horizontal displacement of wall $U_{x}$ is equal in both cases for building model, with a very slight difference in curves. Thus, the way the building is modelled does not affect the wall's horizontal displacement.

- The maximum bending moment of wall is $1.4 \%$ greater in the case in which the building is modeled as a plate than in the case where the building is modeled as a whole building. Thus, the way the building is modelled does not affect the wall's bending moment.

- After the comparison between 2D and 3D FEM simulating the deep excavation, 3D models are found to be more accurate for models with additional details that can't be modelled using 2D software, such as a case with corner reinforcement like our case.

\section{References}

[1] Horodecki, G. A., \& Dembicki, E. (2012). Impact of deep excavation on nearby urban area. 6.

[2] Sevencan, O., Ozaydin, K., \& Kilic, H. (2013). Numerical Analyses of Soil Deformations Around Deep Excavations. 3,10 .

[3] Kenawi, M. A., \& Ibrahim, M. G. (2017). Interaction Analysis of Supporting Excavation Piles and Adjacent Existing Strap Footing. 5(4), 8.

[4] Dhatrak, D. A. I., Kulkarni, S., \& Student, P. G. (2007). Effect of Deep Excavation Adjacent to Pile Structure. 5(4), 6. 
[5] Zumrawi, M. M. E., \& El-Amin, A. (2016). Importance of Deep Excavation Support and Its Influence on Adjacent Buildings. 6. 